DOI: $10.4274 /$ tpa.46.69

\title{
"Kinesio Tape" bantlama yönteminin miyelomeningoselli çocuklarda oturma şekli ve işlevsel bağımsızlık üzerine etkisi: dört olgu sunumu
}

\author{
The effects of kinesio taping on sitting posture and functional independence in \\ children with myelomeningocele: report of four cases
}

\author{
Tülay Tarsuslu Şimşek, Bahriye Türkücüoğlu*, Gonca Üstünbaş* *, Nilay Çokal ** \\ Abant lizzet Baysal Ünivesritesi, Fizik Tedavi ve Rehabilitayson Bölümü, Bolu, Türkive \\ *Sakarya Özel Konuk Özel Eğitim ve Rehabilitasyon Merkezi, Fizik Tedavi ve Rehabilitasyon Bölümü, Sakarya, Türkive \\ **Düzce Özel IIlgim Özel Eğitim ve Rehabilitasyon Merkezi, Fizik Tedavi ve Rehabilitasyon Bölümü, Düzce, Türkive \\ ***Zonguldak Özel IIlkcan Özel Eğitim ve Rehabilitasyon Merkezi, Fizik Tedavi ve Rehabilitasyon Bölümü, Zonguldak, Türkiye
}

\section{Özet}

Miyelomeningosel, nöral arkın kapanma bozukluğu olup, çocuklarda beden yapı ve işlev bozuklukları, katııım kısıtılığı ve etkinlik sınırlanmasına neden olmaktadır. Miyelomeningoselli çocukların rehabilitasyonunda beden yapı ve işlevlerini korumak ve işlevsel bağımsızlığı kazandırmak en önemli hedeflerdendir. Bu çalışmada, miyelomeningosel tanılı dört olguda Kinesio Tape bantlama yönteminin oturma şekli ve işlevsel bağımsızlık üzerine etkisi incelenmiştir. (Türk Ped Arş 2011; 46: 177-80)

Anahtar sözcükler: Kinesio Tape, myelomeningosel, oturma şekli, oturmanın değerlendirmesi

\section{Summary}

Myelomeningocele, is a defect of neural arch which causes body structure and function disorders, participation restrictions and activity limitation in children. Keeping body structure and functions, and gaining functional independence are the most important goals in the rehabilitation of children with myelomeningocele. In this study, we analysed the effects of Kinesio Taping on sitting posture and functional independence in 4 cases with myelomeningocele. (Turk Arch Ped 2011; 46: 177-80)

Key words: Myelomeningocele, Kinesio Tape, sitting assessment, sitting posture

\section{Giriş}

Miyelomeningosel (MM), nöral arkın kapanma bozukluğu olup (1), beden yapı ve işlev bozukluğu, katııım kısıtIılı̆ı ve etkinlik kısıtlamasına neden olmaktadır (2). Spinal etkilenimin yanı sıra, birçok hasta kas zayıflığı ve alt ekstremitelerde duyu kaybı, üst ekstremite disfonksiyonu, mesane ve bağırsak enkontinansı, bilişsel disfonksiyona neden olan hidrosefali ve Arnold Chiari II malformasyonundan etkilenebilmektedir $(3,4)$. Miyelomeningoselin önemi yalnızca spinal etkilenmenin olması değil, aynı zamanda, nörolojik kayıplarla belirgin olan merkezi sinir sisteminin etkilenmesidir $(5,6)$. Miyelomeningoselli hastalarda çocukluk ve ergenlik çağında meydana gelen fiziksel ve fizyolojik sorunlar için çok merkezli yaklaşımlar gerekmektedir.

Miyelomeningoselde fizyoterapi yaklaşımları yaygın olarak uygulanmakta olup, rehabilitasyon yaklaşımları kas kuvveti ve tonusunu arttırmak, kontraktürleri önleyerek çocuğun gelişim ve işlevselliğini korumak hedefini taşır $(6,7)$. Miyelomeningoselli çocukların oturma ve yürüme işlevlerini geliştirmek amacıyla fizyoterapi uygulamalarına ek olarak farklı yaklaşımlar da uygulanabilmektedir (çeşitli oturma düzenekleri, cerrahi uygulamalar, elektro-mekanik araçlar, vs) $(8,9)$. Bu çalışmada, 1996 yllında Dr. Kenzo Kase tarafından 
tanımlanan ve çocuk rehabilitasyon kliniklerinde fizyoterapi programlarına ek olarak zayıf kasları kuvvetlendirmek, eklem "instabilitesini" kontrol etmek, duyusal uyarılmayı arttırmak, işlevsel motor becerileri arttırmak, postüral düzgünlüğe yardımcı olmak ve işlevselliğe destek olmak amacıyla kullanılabilen "Kinesio Tape" (KT) bantalama yönteminin dört olguda oturma şekli ve işlevsel bağımsızlık üzerine etkisi incelenmiştir $(10,11)$. Dr.Kenzo, egzersizle birlikte kullanılan KT uygulamasının daha iyi sonuçlar verebileceğini belirtmiştir $(10,11)$. Bu çalışmada da KT uygulaması, düzenli olarak fizyoterapi ve rehabilitasyon programı alan çocuklara uygulanmıştır.

\section{Olgu Sunumu}

Çalıșmaya miyelomeningosel tanısı konan dört olgu dahil edilmiștir. Çalıșmanın başında hem çocuklar hem de aileleri çalışma hakkında bilgilendirilmiş ve çalışma için olurları alınmıştır. Çalışmaya yalnızca ailelerinin katılmak istediklerini belirttikleri çocuklar dahil edilmiştir. Çalışmaya dahil edilme ölçütleri: miyelomeningosel tanısı olan, fizyoterapi ve rehabilitasyon programı alan, karın ve sırt kasları zayıf ve ilişki kurulabilen çocuklar olarak belirlenmiştir. Kalça çıkığı olan, verilen komutları anlamayacak kadar algılama sorunu olan ve son bir yıl içerisinde omurga cerrahisi geçiren çocuklar çalışmaya dahil edilmemişlerdir.

Çalışmaya dahil edilen olgulara ait tanımlayıcı bilgiler Tablo 1'de gösterilmiştir. Çalışmaya dahil edilen olgular 3-4 yıl arasında değişen sürelerde fizyoterapi ve rehabilitasyon programı almakta idi (Tablo 1).

\section{Değerlendirme ölçütleri}

Oturmada denge ve postürü değerlendirmek için Oturma Değerlendirme Skalası (SAS) kullanılmıştır. Bu beş bölümden oluşan (baş, gövde, ayak, el ve kol), oturma düzgünlüğü ve dengesini değerlendiren bir skaladır. Olgu uygun bir tabure üzerinde oturmaktayken baş, gövde ve ayak kontrolüne bakılır. Kol ve el işlevlerini değerlendirmek için hastadan bir nesneyi kavraması istenir. Her bir bölüm 1'den (zayıf) 4'e (iyi) kadar derecelendirilir (12).

Oturmada Postüral Kontrol Ölçümü (SCPM), oturma şeklini değerlendirmek amacıyla kullanılmıştır. Bu ölçüm, postüral bozukluğu değerlendirdiği gibi, oturmanın postüral kontrole etkisinini de değerlendirmektedir. Kişisel bilgilerin yer aldığı (tanı, yaş, doğum tarihi, vs) bölüm, oturmadaki düzgünlük ve üst ekstremite işlevini değerlendiren bölüm olmak üzere üç bölümden oluşur. Temel duruşa göre oluşan sapmalar 1'den (şiddetli bozukluk) 4'e (normal) kadar derecelendirilir. Oturmada düzgünlük bölümünden en yüksek 84 puan, üst ekstremite işlevi bölümünden ise 48 puan alınabilmektedir (13).

Olguların işlevsel bağımsızlık seviyesini değerlendirmek amacıyla çocuklar için işlevsel bağımsızlık ölçümü (WeeFIM) kullanılmıştır. WeeFIM, altı alt bölüm ve 18 madde içerir: kendine bakım (6 madde), sfinkter kontrolü ( 2 madde), transfer ( 3 madde), lokomosyon ( 2 madde), iletişim (2 madde) ve sosyal durum ( 3 madde). Her bir madde 1 ile 7 arası puanlarla değerlendirilir. 1 çocuğun tamamen bağımlı olduğunu, 7 ise tamamen bağımsız olduğunu ifade eder. WeeFIM'den en düşük 18 , en yüksek 126 puan alınabilmektedir (14).

\section{Uygulama}

"Kinesio Tape" uygulaması erektör spinalara sakral 1 spinal seviyeden servikal 7 spinal seviye boyunca Dr. Kase'in önerdiği şekilde "origodan insersiyoya" olacak

\begin{tabular}{|c|c|c|c|c|c|c|c|}
\hline & Cinsiyet & Yaş (yıl) & Boy (cm) & Kilo (kg) & $\begin{array}{l}\text { Varsa kullandığı } \\
\text { yardımcı cihaz }\end{array}$ & $\begin{array}{l}\text { Fizyoterapi-rehabilitasyon } \\
\text { alma süresi (yıl) }\end{array}$ & Seviye \\
\hline I. Olgu & $\mathrm{KIz}$ & 9 & 112 & 34 & KAFO* & 3 & Lumbosakral \\
\hline II. Olgu & Erkek & 5 & 85 & 21 & KAFO & 4 & Lumbosakral \\
\hline III. Olgu & $\mathrm{KIz}$ & 8 & 105 & 28 & - & 3 & Torakolumbal \\
\hline IV. Olqu & $\mathrm{KIZ}$ & 9 & 110 & 30 & - & 2 & Lumbosakral \\
\hline
\end{tabular}

*KAFO: Kalça-ayak-ayak bileği ortezi

Tablo 2. Olguların KT öncesi ve sonrası SCPM, SAS, WeeFIM değerleri

\begin{tabular}{|l|c|c|c|c|c|c|c|c|}
\hline \multicolumn{9}{|c|}{ KT $^{\star}$ öncesi } \\
\hline & SCPM $^{\star}$ düzgünlük sonrası & SCPM işlev & SAS $^{\star \star}$ & WeeFIM $^{\star \star *}$ & SCPM düzgünlük & SCPM işlev & SAS & WeeFIM \\
\hline I.Olgu & 51 & 36 & 17 & 93 & 55 & 47 & 17 & 98 \\
\hline II.Olgu & 58 & 43 & 16 & 75 & 60 & 44 & 18 & 77 \\
\hline III.Olgu & 53 & 44 & 17 & 76 & 54 & 44 & 17 & 89 \\
\hline IV.Olgu & 61 & 37 & 16 & 81 & 64 & 39 & 17 & 84 \\
\hline
\end{tabular}

$\mathrm{KT}^{*}$ : "Kinesio Tape"

**SCPM: Oturmada Postüral Kontrol Ölçümü

${ }^{* *}$ SAS: Oturma Değerlendirme Skalası

****WeeFIM: Çocuklar için işlevsel bağımsızlık düzeyi 
şekilde uygulanmıştır (11). Uygulamada $5 \mathrm{~cm}$ 'lik KT (Kinesio Tex, Gold) erektör spinalara daha çok duyusal uyarı sağlamak amacıyla "fan tekniği" şeklinde kullanılmıştır ve uygulama iki taraflı olarak yapılmıştır (Resim 1). "Kinesio Tape" uygulaması yapılan çocuklarda bant üç gün boyunca bekletilmiş, üç gün sonrasında bant sökülmüş ve 24 saat boyunca serbest bırakılan bölgeye fizyoterapist tarafından tekrar KT uygulaması yapılmıştır.

Çalışmaya katılan olgular 12 hafta boyunca, haftada üç gün, birer saatlik fizyoterapi ve rehabilitasyon programına alınmışlardır. Fizyoterapi ve rehabilitasyon programı kapsamında olgulara çalışma boyunca ağırlıklı olarak oturma pozisyonunda üst ekstremite kavrama, bırakma ve uzanma etkinlikleri, oturma ve gövde dengesini arttırmaya yönelik egzersizler ile oturma pozisyonuna gelme etkinlikleri çalıştıııımıştır.

Olgulara ait KT uygulama öncesi ve sonrası WeeFIM, SCPM ve SAS değerleri Tablo 2'de gösterilmiştir.

\section{Tartışma}

Kas güçsüzlüğü ve omurga deformiteleri nedeniyle duruş bozukluğu gelişen MM'li hastalarda oturma ve duruş düzgünlüğünü sağlamak, omurga deformiteleri ve gelişebilecek kalça ve alt ekstremite deformitelerini, bası yaralarını önlemek ve el etkinliklerini geliștirmek açısından önem taşımaktadır $(15,16)$. Bu çalışmada, MM tanısı konan dört olguda KT uygulamasının oturma şekli ve işlevsel bağımsızlık üzerine etkisine bakılmış ve sonuçta, bütün olguların SCPM, SAS ve WeeFIM değerlerinde artış gözlenmiştir. Olgularımızın üçü lumbosakral etkilenimli, biri ise torakolumbal seviye etkilenimli olup, en fazla gelişme lumbosakral etkilenimli olgularda saptanmıştır.

"Kinesio Tape" uygulamalarının kullanımının yaygınlaşması ile birlikte, literatürde de KT'nin etkilerini inceleyen

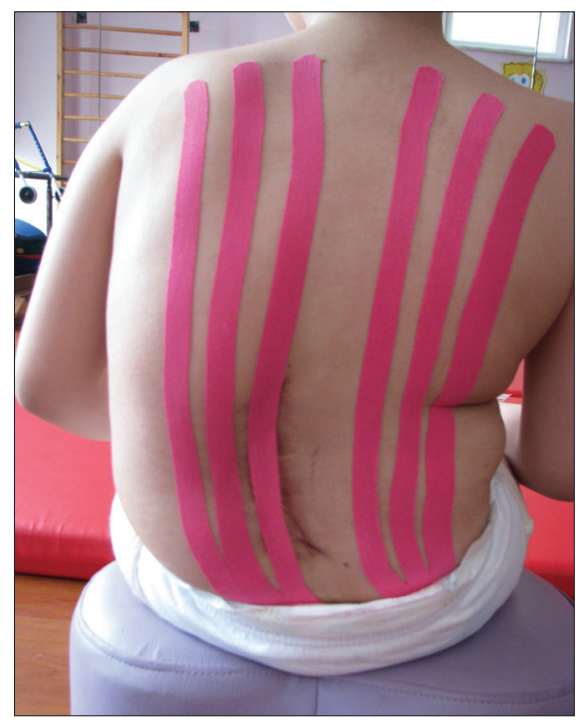

Resim 1: Olgularda "Kinesio Tape" uygulaması çalıșma sayısında artış olduğu dikkati çekmektedir. Nörolojik etkilenimli hastalarda farklı amaçlarla kullanılan KT uygulamasının MM'li olgularda kullanımı ile ilgili literatürde çalışma bulunmamaktadır. Bu çalışma bu konuda yapılıış ilk çalışma özelliğini taşımaktadır.

Yapılan bazı çalışmalarda, KT'nin gövde fleksiyon normal eklem hareketinin (ROM) arttırımasında, akut wiplash yaralanması (motorlu taşıt kazaları esnasında, önden ya da arkadan çarpmalar sonucu, baş ve boyun ani olarak öne veya arkaya hareket etmesi) olan hastalarda, patellofemoral ağrı sendromunun sağaltımında yararlı olabileceği belirtilmiştir (17-19). Jaraczewska ve Long'un (20) çalışmasında, diğer sağaltım yöntemleriyle birlikte uygulanan KT'nin hemiplejik hastalarda kas etkinliğini kolaylaştırma veya yok etmede, ağrıyı azaltmada, "propriyoseptif feed-back" mekanizmasını arttırmada ve beden düzgünlüğünü sağlamada etkili olduğu bulunmuştur. Yasukawa ve ark'larının (10) bir çalışmasında ise, akut çocuk rehabilitasyon kliniklerinde kullanılan KT uygulamasının üst ekstremite kontrolünü ve işlevini geliştirdiğini, hastanede yatış süresi boyunca iş-meşguliyet terapi programlarına ek olarak kullanılmasının yararlı olacağı belirtilmiştir (10). Cepeda ve ark'larının (21) hipotoni tanılı çocuklarda yaptıkları çalışmada, karın kaslarına uygulanan KT'nin çocuklarda sırt üstü yatar pozisyondan oturur pozisyona geçişi arttıran terapötik bir yöntem olduğu belirtilmiştir. Biz de fizyoterapiye ek olarak beden dengesini artırmak, propriyoseptif algıyı arttırarak, beden düzgünlüğünü sağlamak ve zayıf kasları desteklemek amacıyla uygulamış olduğumuz KT uygulamasının çocukların işlevsel düzeylerine ve oturma şekillerine olumlu etkisinin olduğunu gördük. Özellikle I. olgumuzun üst esktremite işlevlerinde diğer olgulara göre daha fazla bir artışın olduğu gözlendi. Miyelomeningoselli çocuklarda üst ekstremite işlevlerinin artışı özellikle günlük yaşam etkinliklerinde (kendine bakım etkinlikleri) bağımsızlığı da beraberinde getiren önemli bir işlevdir. Nitekim, bütün olgularımızın günlük yaşam etkinliklerinde belirgin artış gözlendi. Aynı şekilde, olgularımızın otururken beden düzgünlüğü ve kontrolünde de artış kaydedildi. Sonuç olarak, çalışmamızda KT uygulamasının MM tanılı olgularda kullanımının yararlı olduğunu bulduk. "Kinesio Tape" bantlamasının klinikte, oturma dengesi iyi olmayan, gövde kaslarında zayıflık ve denge sorunu olan çocuklarda fizyoterapi ve rehabilitasyon programlarına ek olarak kullanılabileceğini düşünüyoruz.

Bu çalışma, bu alanda yapıımış ilk çalışmadır ve bundan sonra KT uygulaması ile ilgili yapılacak çalıșmalara ışık tutabilecek özellikte olması dolayısıyla önem taşıdığını düşünüyoruz. Bu konu ile ilgili olgu sayısı arttırılarak ve kontrol grupları oluşturularak yapılacak daha çok çalışmalara intiyaç vardır.

Çıkar çatışması: Bildirilmedi. 


\section{Kaynaklar}

1. Fürderer S, Hopf C, Schwarz M, Voth D. Orthopedic and neurosurgical treatment of severe kyphosis in myelomeningocele. Neurosurg Rev 1999; 22: 45-9.

2. Hinderer KA, Hinderer SR, Shurtleff DB. Myelodysplasia. In: Campbell SK, Vander Linden DW, Palisano RJ (eds). Physical Therapy for Children. 3th ed. St. Louis, MO: Saunders Elsevier, 2006, 735-89.

3. Hunt GM, Oakeshott P, Kerry S. Link between the CFS hunt and achievement in adults with spina bifida. J Neurol Neurosurg Psychiatry 1999; 67:591-5.

4. Schoenmakers MA, Uiterwaal CS, Gulmans VA, Gooskens RH, Helders PJ. Determinants of functional independence and quality of life in children with spina bifida. Clin Rehabil 2005; 19: 677-85.

5. Tsai PY, Yang TF, Chan RC, Huang PH, Wong TT. Functional investigation in children with spina bifida-measured by the Pediatric Evaluation of Disability Inventory (PEDI). Childs Nerv Syst 2002; 18: 48-53.

6. Hinderer KA. Hinderer SR. Shurtleff DB. Mylelodysplasia. İn: Campbell SK, Palisano RJ, vander Linden DW. Physical therapy for children. $2^{\text {nd }}$ ed. Philadelphia: WB Saunders Co, 2000: 735-60.

7. Ryan KD, Ploski C, Emans JB. Myelodysplasia-the musculoskeletal problem: habilitation from infancy to adulthood. Phys Ther 1991; 71: 935-45.

8. Wai EK, Young NL, Feldman BM, Badley EM, Wring JG. The relationship between function, self-perception, and spinal deformity: Implications for treatment of scoliosis in children with spina bifida. J Pediatr Orthop 2005; 25: 64-9.

9. Vaisbuch N, Meyer S, Weiss PL. Effect of seated posture on interface pressure in children who are able-bodied and who have myelomeningocele. Disabil Rehabil 2000; 22: 749-55.

10. Yasukawa A, Patel P, Sisung C. Pilot study: Investigation the effects of Kinesio Taping in an acute pediatric rehabilitation setting. Am J Occup Ther 2006; 60: 104-10.

11. Kase K, Martin P, Yasukawa A. Kinesiotaping in pediatrics. Fundamentals and whole body taping. Kinesio Taping Association, Albuquerque, New Mexico, USA, 2006: 9-30.
12. Myhr U, von Wendt L, Norrlin S, Radell U. Five-year follow-up of functional sitting position in children with cerebral palsy. Dev Med Child Neurol 1995; 37: 587-96.

13. Fife SE, Roxborough LA, Armstrong RW, Harris SR, Gregson $\mathrm{JL}$, Field D. Development of a clinical measure of postural control for assessment of adaptive seating in children with neuromotor disabilities. Phys Ther 1991; 71: 981-93.

14. Erkin G, Aybay C, Kurt M, Keles I, Cakci A, Ozel S. The assessment of functional status in Turkish children with cerebral palsy (a preliminary study). Child Care Health Dev 2005; 31: 719-25.

15. Fürderer S, Eysel P, Hopf C, Heine J. Sagittal static imbalance in myelomeningocele patients: Improvement in sitting ability by partial and total gibbus resection. Eur Spine J 1999; 8: 451-7.

16. Höglund A, Norrlin S. Influence of dual tasks on sitting postural sway in children and adolescents with myelomeningocele. Gait Posture 2009; 30: 424-30.

17. Yoshida A, Kahanov L. The effect of kinesio taping on lower trunk range of motions. Res Sports Med 2007; 5: 103-12.

18. González-Iglesias J, Fernández-de-Las-Peñas C, Cleland JA, Huijbregts $P$, Del Rosario Gutiérrez-Vega M. Short-term effects of cervical kinesio taping on pain and cervical range of motion in patients with acute whiplash injury: a randomized clinical trial. J Orthop Sports Phys Ther 2009; 39: 515-21.

19. Chen WC, Hong WH, Huang TF, Hsu HC. Effects of kinesio taping on the timing and ratio of vastus medialis obliquus and vastus lateralis muscle for person with patellofemoral pain. $J$ Biomech XXI ISB Congress, 1-5 July 2007, Taiwan, Podium Sessions 2007; 40: 318.

20. Jaraczewska E, Long C. Kinesio taping in stroke: improving functional use of the upper extremity in hemiplegia. Top Stroke Rehabil 2006; 13: 31-42.

21. Cepeda JP, Fishweicher A, Gleeson M, Greenwood S, Motyka-Miller C. Does Kinesio Taping of the abdominal muscles improve the supine-to-sit transition in children with hypotonia? 2008, http://www.kinesiotaping.com/kinesiotaping-for-abdominal-muscles-to-improve-the-supine-tosit-transition-in-children.php. (Erişim: 05.10.2009). 